\title{
RESEÑA DE TESIS DOCTORAL: EL MARKETING DE AFILIACIÓN EN EL CONTEXTO DE LAS AGENCIAS DE VIAJES
}

\author{
Magdalena Rodríguez Fernández ${ }^{1}$ \\ Universidad de A Coruña \\ mmrodriguez@udc.es
}

Material original autorizado para su primera publicación en la revista académica REDMARKA. Revista Digital de Marketing Aplicado

http://doi.org/10.17979/redma.2012.03.08.4764

Tesis Doctoral de Clide Rodríguez Vázquez, El Marketing de Afiliación en el contexto de las agencias de viajes. Tesis doctoral presentada y defendida en sesión pública el 21 de Marzo de 2012, en la Facultad Sociología de la Universidad de A Coruña, calificada de Sobresaliente cum Laude.

Palabras clave: Turismo, Agencias de Viajes, Marketing Afiliación, Redes Sociales, Publicidad

\section{PhD REVIEW}

Clide Rodríguez Vázquez, El Marketing de Afiliación en el contexto de las agencias de viajes. PhD presented and defended on March the 21th 2012, in the Sociology Faculty of University of A Coruña, qualified Outstanding cum Laudem.

Keywords: Tourism, Travel Agencies, Affiliate Marketing, Social Networking, Advertising.

\footnotetext{
${ }^{1}$ Doctora en Ciencias Económicas y Empresariales por la Universidad de A Coruña, Licenciada en Ciencias Económicas y Empresariales por la Universidad de Santiago de Compostela, Postgrado en Economía y Calidad en el Sector turístico por la Universidad de A Coruña, Profesora en el área de Comercialización e Investigación de Mercados en la Facultad de Economía y Empresa de la UDC, en La Escuela Universitaria de Turismo de A Coruña, y en el Máster Oficial en Dirección y Planificación del Turismo de la Universidad de A Coruña.
} 
El impacto de las tecnologías de la información y de la comunicación ha supuesto en los últimos tiempos uno de los acontecimientos históricos más relevantes para la sociedad actual.

La irrupción en el mercado de canales de comunicación, comercialización y distribución como Internet, ha posibilitado poner al alcance de las organizaciones y del consumidor turístico poderosas redes y tecnologías, asistiendo de este modo al nacimiento de nuevos conceptos y modelos de gestión en el contexto turístico. La aplicación de herramientas de información, de gestión y contratación de productos en el ámbito turístico ha contribuido a un cambio de paradigma de los clientes.

Ante este nuevo contexto esta Tesis Doctoral muestra por tanto, cómo en el marco de las agencias de viajes, al ser consumidoras y proveedoras de información empresarial y turística, los posibles cambios que introduce la sociedad de la información deben ser capaces de potenciar la utilidad y capacidad funcional de estas empresas. Internet se ha constituido para las agencias en un escaparate virtual informativo y comercial de ámbito internacional, convirtiéndose en un complemento a la labor presencial.

Es importante ser conscientes también de que estamos ante un nuevo escenario, en el que los usuarios están más informados, son más participativos, lo que contribuye de ese modo a que sean más exigentes, ello les lleva a solicitar todo tipo de información sobre la empresa con la que tratan y acerca de sus productos o servicios buscando demandar soluciones totalmente personalizadas y adaptadas a sus necesidades.

En este sentido los medios digitales interactivos como Internet permiten crear un vínculo directo entre las empresas y sus clientes, al ofrecer un servicio ininterrumpido y global. Esta nueva situación de interacción entre el productor y el 
consumidor posibilita la personalización de productos y servicios, así como la participación activa del cliente en su realización.

Coyunturalmente son varios los aspectos que confluyen, por un lado, nos enfrentamos a un momento de crisis económica, y por otro, se ha llegado a una situación en la que la oferta de productos y servicios supera claramente a la demanda existente, situación que provoca una gran rivalidad a nivel empresarial. Mantener las cuotas de mercado y fidelizar a los clientes constituye el objetivo principal de las empresas, la cuestión es ser diferente a los demás. Es por tanto imprescindible conocer al cliente, saber cuáles son sus necesidades, expectativas y qué productos son necesarios para satisfacerlas.

Ante todos estos aspectos que se vislumbran en los entornos turísticos actuales, esta Tesis Doctoral ocupa un importante lugar.

En este sentido el tema y objeto central de la misma se fundamenta en analizar la situación de las agencias de viajes españolas, como vehículo de intermediación turística y de comercialización de los productos turísticos, y su relación con las Tecnologías de la Información, en concreto con las herramientas que tienen a su alcance para conseguir la fidelización de los clientes, como es el Marketing de Afiliación. Trata en definitiva de analizar la importancia que dicha herramienta presenta para estas agencias y para la distribución turística en general, teniendo en cuenta que los grandes líderes del mercado a nivel internacional, deben gran parte de su éxito a sus grandes redes de afiliados.

Ante este panorama y en pleno debate sobre la supervivencia de las agencias de viajes tradicionales, el Marketing de Afiliación emerge como una herramienta que ayudará a las agencias a adaptarse a los nuevos tiempos y a las necesidades de los clientes actuales, minimizando los costes de comercialización y ajustándolos a los resultados. 
En este contexto esta Tesis analiza el conocimiento que existe sobre el Marketing de Afiliación, los aspectos inherentes a esta herramienta online y cómo es su implementación en las agencias de viajes en España tanto offline como online, así como en el ámbito del marketing en general. La finalidad se fundamenta en delimitar cuáles son los Modelos de Negocio en los que se desarrolla el Marketing de Afiliación, así como las herramientas que utilizan y las formas de remunerar estas acciones.

La Tesis Doctoral se estructura así en siete capítulos, divididos en dos partes, una relativa a los fundamentos teóricos y la otra, relacionada con la aplicación práctica desarrollada en esta investigación.

En la primera parte y en relación al marco teórico, cabe precisar que lo configuran cuatro capítulos en los cuales se exponen, a través de la revisión de la literatura pertinente, conceptos relacionados que conforman los pilares básicos de esta investigación.

Así el Capítulo I explica la evolución de Internet y su relación con la Publicidad y el Sector Turístico, se investiga además la situación de España ante el desarrollo de Internet y su relación con los usuarios, así como con la publicidad actual y con el sector turístico.

En el Capítulo II se estudian los orígenes e importancia de las Redes Sociales como génesis de la idea de negocio del Marketing de Afiliación.

En el Capítulo III se lleva a cabo un estudio pormenorizado del Marketing de Afiliación como herramienta, de sus orígenes, de las tipologías existentes, de sus ventajas e inconvenientes, de los aspectos esenciales en el conocimiento de los 
programas de afiliación y de las principales plataformas de afiliación que existen en España.

Y en el cuarto y último capítulo que conforma el marco teórico la autora de la Tesis Doctoral analiza la relación existente entre las agencias de viajes y el Marketing de Afiliación, para ello investiga la situación del sector turístico mundial y español y su relación con las agencias de viajes, las agencias offline frente a las online y la relación entre la publicidad y las agencias.

La segunda parte de la Tesis Doctoral como ya se ha explicitado anteriormente corresponde a la Aplicación Práctica, se asientan por tanto aquí los tres últimos capítulos de la investigación.

Así el Capítulo V incluye, en primer lugar, el ámbito de estudio, los objetivos de la investigación y las hipótesis de trabajo. Sobre la base de los fundamentos teóricos recogidos a lo largo de la revisión de la literatura y de aquellos aspectos que requieren mayor investigación, la autora formula el cometido global, así como los objetivos secundarios, entre los que se encuentran: obtener información sobre el grado de conocimiento y desarrollo existente del Marketing de Afiliación en España; determinar aspectos inherentes del Marketing de Afiliación para poder conocerlo en mayor profundidad y evaluar cómo es la implementación de esta herramienta en las agencias de viajes y su relación de futuro.

La segunda parte de este capítulo pone de relieve la metodología de la investigación empírica aplicada, donde la utilización de técnicas cualitativas a través de la realización de entrevistas en profundidad a un grupo de profesionales relacionados con el Marketing de Afiliación, el marketing en general y las agencias de viajes, mayoristas, minoristas y online han supuesto una adecuada $\mathrm{e}$ interesante herramienta para analizar los objetivos que se plantean y contrastar las hipótesis pertinentes. 
En el Capítulo VI se exponen los resultados de la investigación empírica, se analizan los objetivos con los resultados obtenidos a través de la confirmación o refutación pertinente, según el caso, de las hipótesis de trabajo postuladas en la investigación.

En el Capítulo VII se recogen las conclusiones, limitaciones y futuras líneas de investigación que se derivan de la Tesis Doctoral: El Marketing de Afiliación en el contexto de las agencias de viajes. La autora detalla las conclusiones más relevantes de la revisión teórica y las implicaciones extraídas de acuerdo con los resultados obtenidos.

Por último, se incluyen las referencias bibliográficas utilizadas y los anexos que muestran, por un lado, el modelo de entrevista utilizado en la recogida de información y que ha sido presentado a las personas entrevistadas, y por otro lado, información adicional como: glosario de términos para una mejor comprensión del marco teórico e información sobre las normativas de las diferentes Comunidades Autónomas españolas relacionadas con las agencias de viajes.

Tras detallar todos los capítulos que configuran la Tesis Doctoral: El Marketing de Afiliación en el contexto de las agencias de viajes. A continuación se establecen los resultados más relevantes obtenidos a través de la investigación empírica:

- Ante la nueva etapa de desarrollo en los canales de comunicación tradicionales, el Marketing de Afiliación e Internet permiten a las agencias de viajes, nuevas oportunidades para realizar una publicidad dirigida a un segmento de demanda específico con los beneficios que de ello se puedan derivar. Sin embargo, la realidad que se desprende de esta Tesis Doctoral según su autora, es que en España el conocimiento y desarrollo de dicha herramienta todavía no es el adecuado para obtener la máxima eficiencia, 
aunque parece que se evidencian cambios que siguen la dirección adecuada para conseguirlo.

- A lo largo de la Tesis Doctoral también se puede observar que el Marketing de Afiliación supone una buena oportunidad para obtener beneficios sin necesidad de realizar grandes inversiones en logística, sin obligaciones financieras ó de gestión administrativa por parte de la red de afiliados, con el añadido de que el resultado puede ser medible, a diferencia de otras estrategias publicitarias, tratándose por lo tanto de una acción comercial rentable.

Además tal y como establece la autora no se puede obviar que el Marketing de Afiliación prolonga el alcance de la marca y el reconocimiento social, al facilitar notoriedad y mayor visibilidad a aquellas empresas integradas en algún programa de afiliación, lo que permite más visitantes de calidad, más ventas a tantos afiliados como miembros tenga la red, convirtiéndolo en un modelo de negocio online que se traduce en diferenciación para la empresa lo cual podría convertirse en una importante ventaja competitiva.

- Por último, se puede observar también a lo largo de la Tesis Doctoral la existencia de una estrecha relación, que los expertos vaticinan de muy duradera, entre el Marketing de Afiliación y el sector de los viajes. Este sector comercializa un producto que se adapta perfectamente al canal online, aunque como se puede observar a lo largo de la investigación, con diferente grado de implementación entre las agencias tradicionales y las online. En este sentido las primeras no disponen ni de la tecnología, ni de las bases de datos adecuadas para desarrollar los programas ni de lo que es más importante, conocimiento suficiente, además de utilizar otro tipo de distribuidores tradicionalmente. Sin embargo la adecuación al medio de las agencias online es perfecta, y tal y como se deprende de los resultados en 
esta Tesis, la implementación de esta herramienta en este contexto ha sido y sigue siendo realmente exitosa. 